- There are two groups of lasers - 'hard', denoting surgical or cutting lasers and 'soft', denoting non-surgical, low-level devices.

- Laser light can be transmitted, reflected, scattered or absorbed by a target tissue, dependant on the absorption characteristics of the tissue.

- Laser-tissue interaction in dental surgery is primarily photothermal, in that incident energy is converted into heat. The level of heat (temperature) will define the target tissue change.

- The nature of the target tissue and a number of laser operating parameters will allow the clinician to provide precise, controlled and predictable laser-tissue interaction.

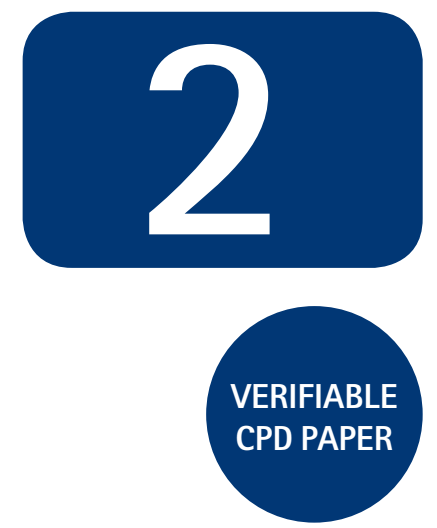

\title{
Laser-tissue interaction
}

\section{S. Parker ${ }^{1}$}

The oral cavity is a unique and complex environment, where hard and soft tissues exist in close proximity, within bacterialaden saliva. All oral tissues are receptive to laser treatment, but the biophysics governing laser-tissue interaction demands a knowledge of all factors involved in delivery of this modality; through this knowledge, correct and appropriate treatment can be delivered in a predictable manner.

\begin{tabular}{l}
\hline LASERS IN DENTISTRY \\
\hline $\begin{array}{l}\text { 1. Introduction, history of lasers and } \\
\text { laser light production }\end{array}$ \\
\hline 2. Laser-tissue interaction \\
3. Low-level laser use in dentistry \\
\hline 4. Lasers and soft tissue: 'loose' soft \\
tissue surgery \\
\hline $\begin{array}{l}\text { 5. Lasers and soft tissue: 'fixed' soft } \\
\text { tissue surgery }\end{array}$ \\
\hline $\begin{array}{l}\text { 6. Lasers and soft tissue: periodontal } \\
\text { therapy }\end{array}$ \\
\hline 7. Surgical laser use in implantology \\
and endodontics \\
\hline 8. Surgical lasers and hard dental \\
tissue
\end{tabular}

${ }^{1}$ General Dental Practitioner,

30 East Parade, Harrogate,

North Yorkshire, HG1 5LT

Correspondence to: Dr Steven Parker

Email: thewholetooth@easynet.co.uk

Refereed Paper

( ) British Dental Journal 2007;

202: 73-81

DOI: $10.1038 /$ bdj.2007.24

\section{LASER TYPES USED IN TISSUE THERAPY}

Anecdotally, there has evolved two groups of lasers, 'hard' and 'soft', in distinguishing their effect on tissue, although this does not relate to target tissue types. 'Hard', or surgical lasers, are essentially high power lasers which achieve desired tissue effect through a direct interaction. For the purposes of clinical dentistry, this effect is primarily photothermal $^{1}$ (Fig. 1), in that incident light energy is absorbed and converted into thermal energy which causes tissue change.

'Soft', or 'low-level' lasers are essentially low power lasers which achieve desired tissue effect through an indirect interaction, known collectively as photobiostimulation, ${ }^{1}$ eg tissue warming, increase of local blood flow and production of 'feel-good' factors, eg endorphins. This latter group will be discussed in detail in a later article.

\section{LASER-TISSUE INTERACTION}

The term 'laser light' is a generic, in that one of the defining properties of laser light - that it is monochromatic - requires a qualifying emission wavelength annotation. However, the use of all laser wavelengths in clinical dentistry serves to effect controlled and precise changes in target tissue, through the transfer of electromagnetic energy. ${ }^{1}$ A competent laser dentist will establish predictable laser-tissue interaction and all its definable outcomes, before embarking on that interaction. It is essential that through the correct choice of a given laser wavelength for treating a given target tissue, a minimum level of power is employed both to effect the desired result and to minimise the risk of collateral damage.

\section{BASIC CONSIDERATIONS}

Incident light energy will interact with a medium (eg oral tissue) that is denser than air, in one of four ways. ${ }^{2}$ These can be listed as follows (Fig 2):

Transmission: in this way, the beam enters the medium, but there is no interaction between the incident beam and the medium. The beam will emerge distally, unchanged or partially refracted.

Scatter: there is some interaction, but this is insufficient to cause complete attenuation of the beam. Scatter will cause some diminution of light energy with distance, together with a distortion in the beam, whereby rays proceed in an uncontrolled direction through the medium. Back-scatter of the laser beam can occur as it hits the tissue; this is seen most in short wavelengths, eg diode, Nd:YAG ( $\geq 50 \%$ back-scatter).

Reflection: the density of the medium, or angle of incidence being less than the refractive angle, results in a total reflection of the beam. In true reflection, the incident and 
Fig. 1 The use of a diode $(810 \mathrm{~nm})$ laser in this crown lengthening procedure illustrates the 'photothermal' nature of laser-tissue interaction. Incident electromagnetic (light) energy is absorbed by gingival pigmented tissue and converted to heat, which effects tissue ablation

Fig. 2 Incident laser light interaction with tissue - event possibilities

Fig. 3 Outline absorption coefficients (haemoglobin, melanin, hydroxyapatite and water) relative to laser wavelength

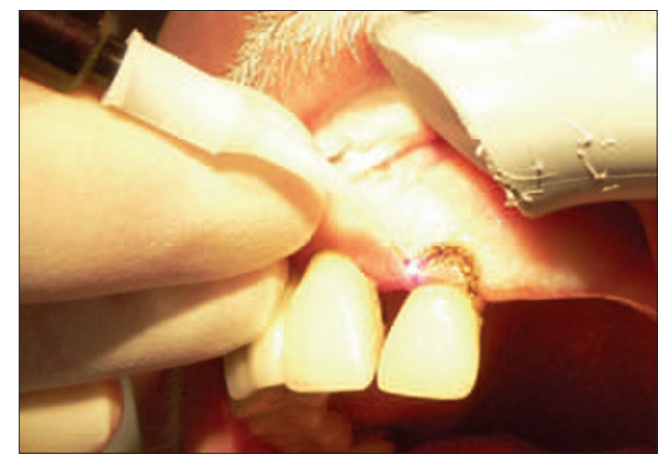

transferred into another form. In clinical dentistry, depending on the value of the energy, there will be a conversion into heat or, in the case of very low values, biostimulation of receptor tissue sites. This can be readily appreciated through an analogy of sun-bathing - the stimulation of 'tanning' melanocytes by low-grade UV sunlight versus the damaging sun-burn with higher exposure values.

In any desired laser-tissue interaction, the achievement of maximum absorption by the target tissue of the incident laser energy emergence angles will be the same or, if the medium interface is rough or non-homogenous, some scatter may occur.

Absorption: the incident energy of the beam is attenuated by the medium and will allow a maximal control of the resultant effects, summarised as follows:

- Absorption is determined by matching incident energy (wavelength) to the electron shell energy in target atoms.
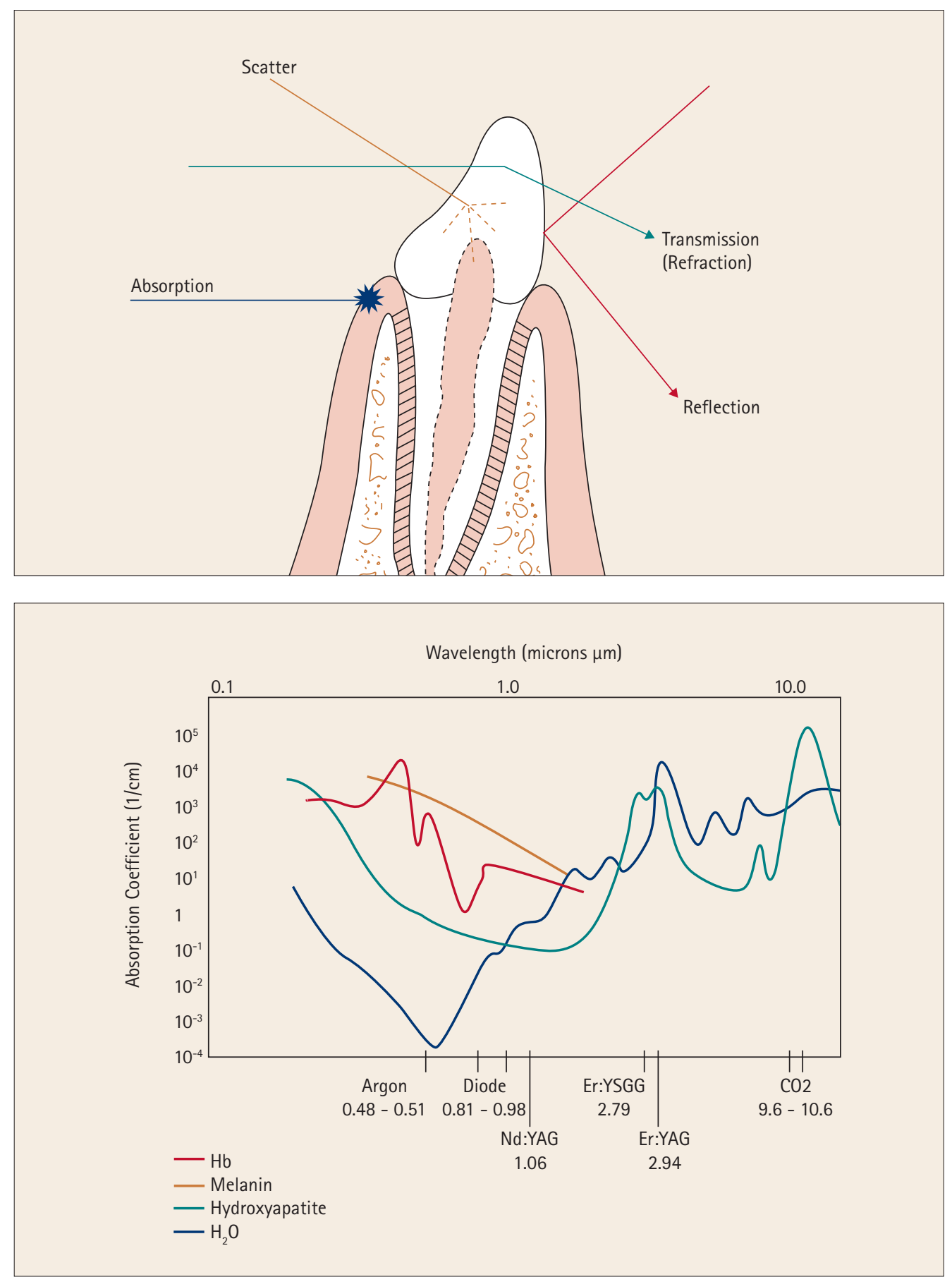

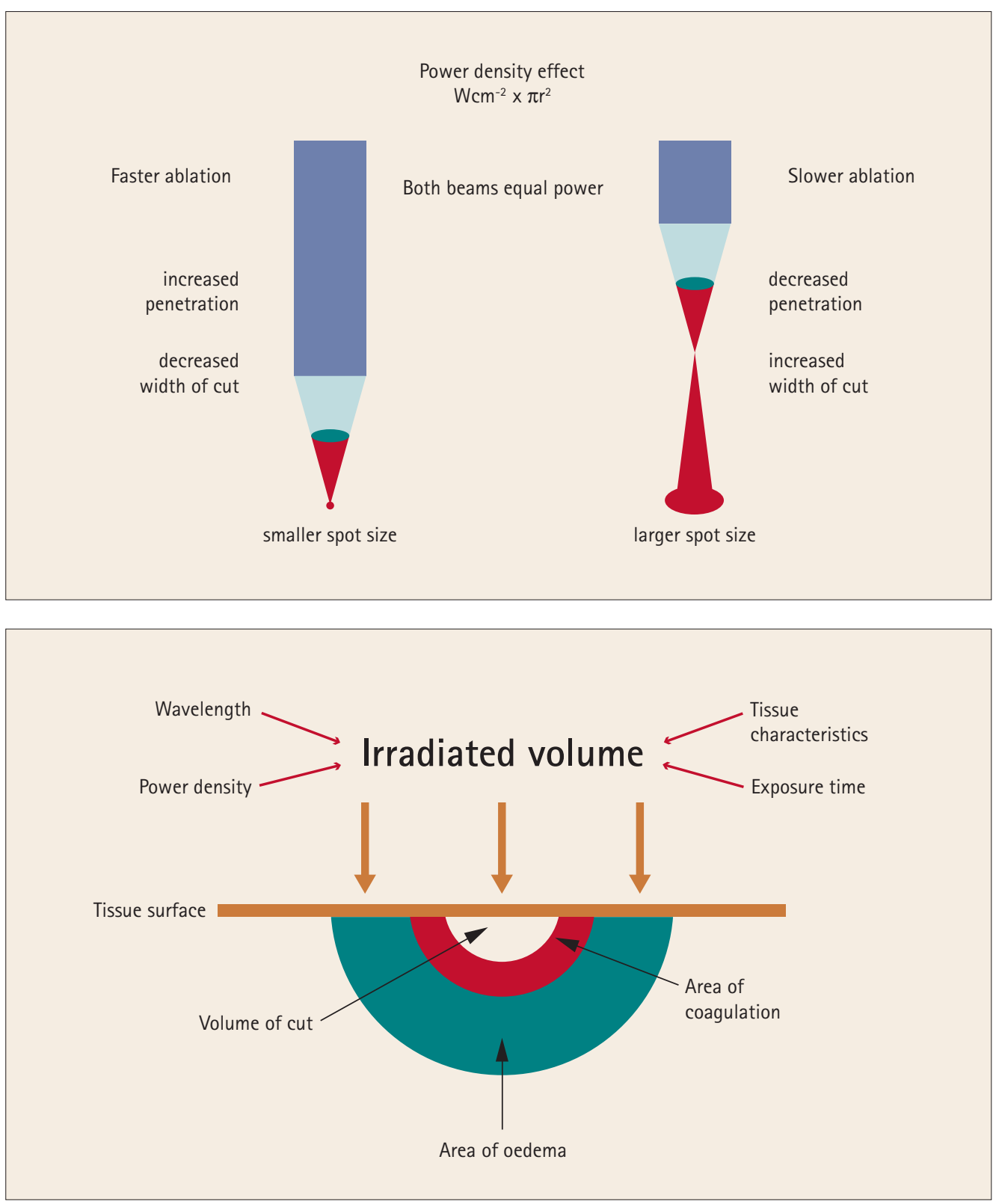

In addition, with regard to surgical lasertissue interaction:

- Absorption of incident energy leads to generation of heat

- Ascending heat levels leads to dissociation of covalent bonds (in tissue proteins), phase transfer from liquid to vapour (in intra- and inter-cellular water), onto phase transfer to hydrocarbon gases and production of residual carbon ${ }^{3}$

- Heat generation can lead to secondary effects through conduction.

The physical change in target tissue achieved through heat transfer is termed photothermolysis. This is further sub-divided, subject to temperature change, phase transfer and incident energy levels, into photopyrolysis, photovaporolysis and photoplasmolysis:

Photopyrolysis: consistent with ascending temperature change from $60^{\circ} \mathrm{C}$ to $90^{\circ} \mathrm{C}$, target tissue proteins undergo morphologic change, which is predominately permanent.
Photovaporolysis: at $100^{\circ} \mathrm{C}$, inter- and intra-cellular water in soft tissue and interstitial water in hard tissue is vaporised. This destructive phase transfer results in expansive volume change, which can aid the ablative effect of the laser by dissociating large tissue elements, especially seen in laser use in hard dental tissue cutting.

Photoplasmolysis: characterised by high temperatures and explosive expansion at micro-tissue and molecular levels, this is observed in ultra-short pulsed lasers, eg $\mathrm{Nd}$ : YAG, Er:YAG, with pulse widths of $<100 \mu \mathrm{s}$. This phenomenon is adjunctive to photothermolysis, whereby a plasma is formed by the ionising effects of the strong electric fields of light waves, and power densities $>10^{10} \mathrm{~W} / \mathrm{cm}^{2}$ are attained. ${ }^{4}$ Photoplasmolysis is achieved photonically in soft tissue and thermionically in hard tissue and is characterised by flashes and popping sounds during laser use. Plasma formation can be beneficial, in that extremely high ablative energies can be produced, but
Fig. 4 Power density effects due to the change in spot size of a focused laser beam. This effect relates to the contact (or non-contact) of the laser hand-piece with the target tissue

Fig. 5 Theoretical zones of tissue change associated with soft tissue exposure to laser light 
Fig. 6 Tissue ablation - Nd:YAG laser. The removal of a fibroma from the lateral aspect of the tongue has resulted in a central zone of ablation and surrounding tissue oedema

Fig. $7 \mathrm{CO}_{2}$ laser and oral epithelium. The zone of ablation is characteristically ' $V$ ' shaped, reflecting little conductive heat effects

Fig. $8 \mathrm{CO}_{2}$ laser interaction with soft tissue. This schematic illustration identifies the vaporisation and dispersal of water within the target tissue

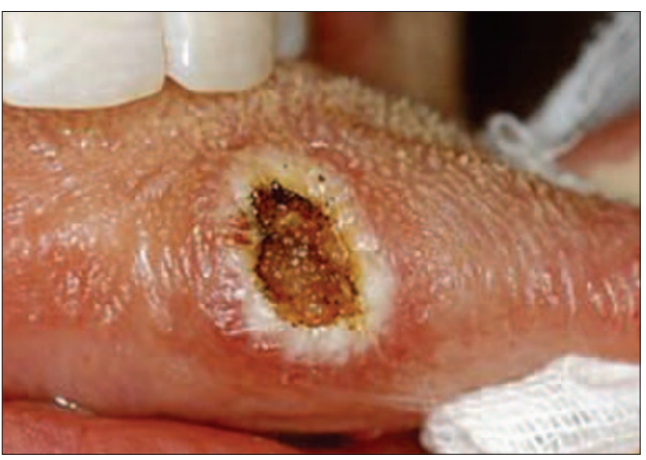

also disruptive in that it can 'shield' the target from further incident light, through the phenomenon of a plasma acting as a 'superabsorber' of electromagnetic radiation. It is considered that, within therapeutic levels of laser power used in dental procedures, photoplasmolysis is a rare occurrence.

\section{THERMAL RELAXATION}

The conversion of electromagnetic energy

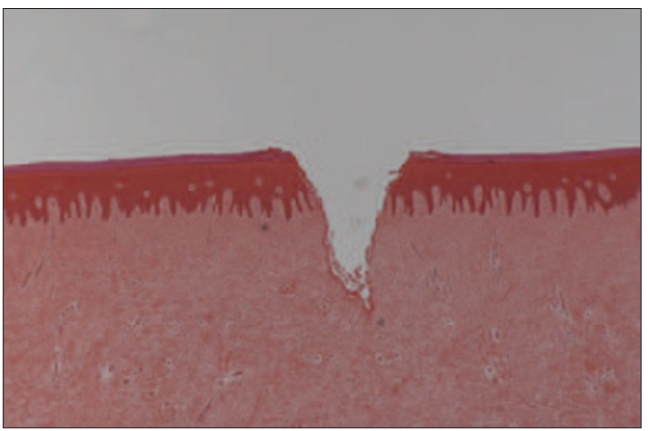

to heat effects in target tissue can only be deemed predictable if unwanted change through conductive thermal spread is prevented. Thermal relaxation is the term applied to the ability to control a progressively increasing heat loading of target tissue. ${ }^{5}$ Assuming fixed values of thermal and light diffusivity for any given tissue, thermal relaxation rates are proportional to the area of tissue exposed and inversely proportional to the absorption coefficient of the tissue. Factors that influence thermal relaxation can be listed as follows.

\section{Laser absorption characteristics}

Laser emission mode, duty cycle: laser light can be emitted as a continuous beam, or in varying forms of pulses with time. Any pulsing of laser light delivery will allow some cooling to occur. Thermal relaxation will occur least with continuous wave emission and maximally in free-running pulsed delivery, with frequent operator-chosen time intervals.

Laser incident power (Joules per second)

Laser power density (Watts per square centimetre): for any chosen level of incident power, the smaller the beam diameter, the greater concentration of heat effects.

Beam movement: relative to tissue site; rapid laser beam movement will reduce heat build-up and aid thermal relaxation.

Endogenous coolant: blood flow.

Exogenous coolant: water, air, pre-cooling of tissue. ${ }^{6,7}$

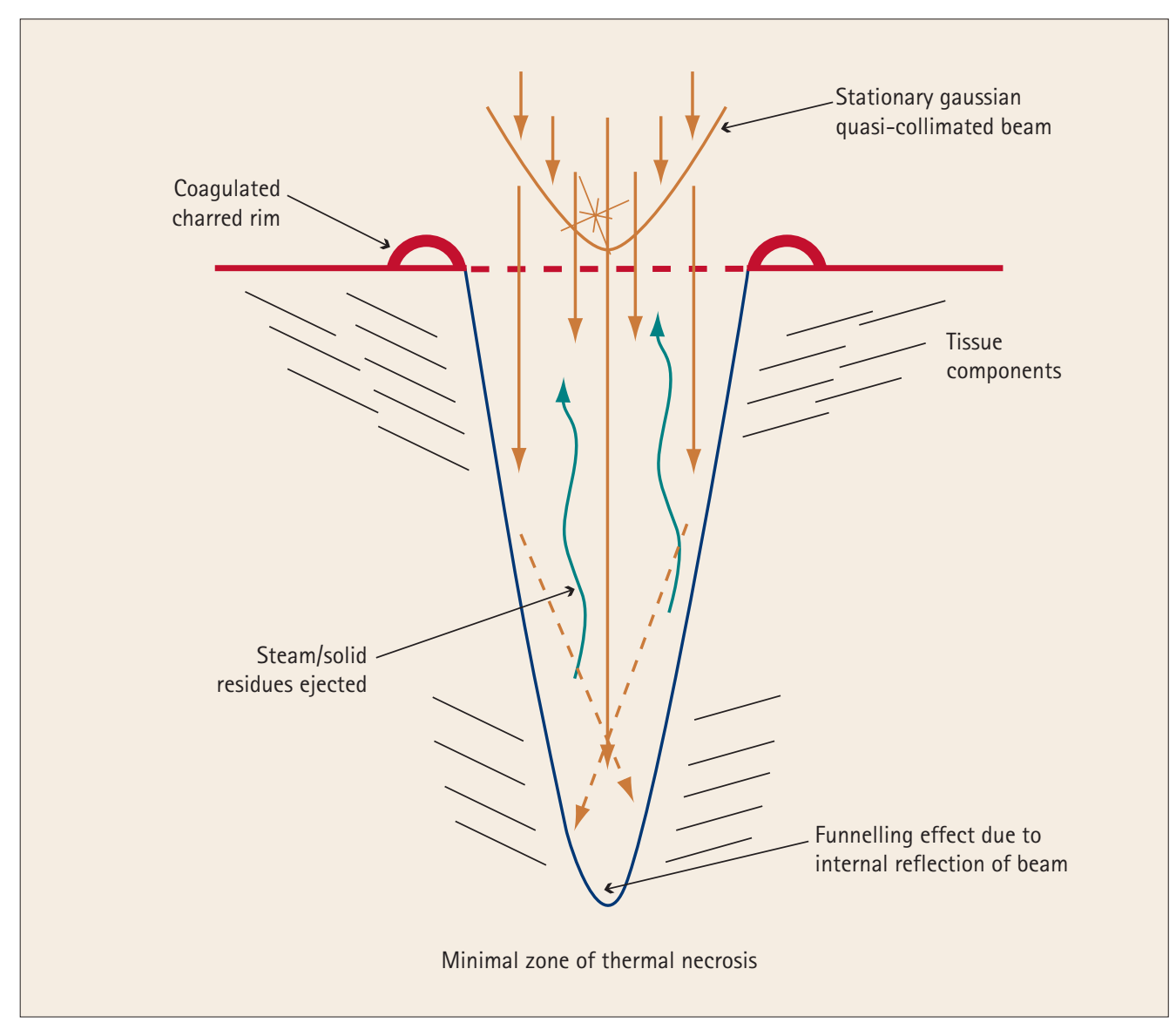


SECONDARY FACTORS AFFECTING ABSORPTION

The following factors will each and collectively affect the absorption of laser light by a target tissue: ${ }^{8}$

- Laser wavelength

- Tissue (composition)

- Tissue thickness

- Surface wetness

- Incident angle of beam

- Exposure time

- Contact vs non-contact modes.
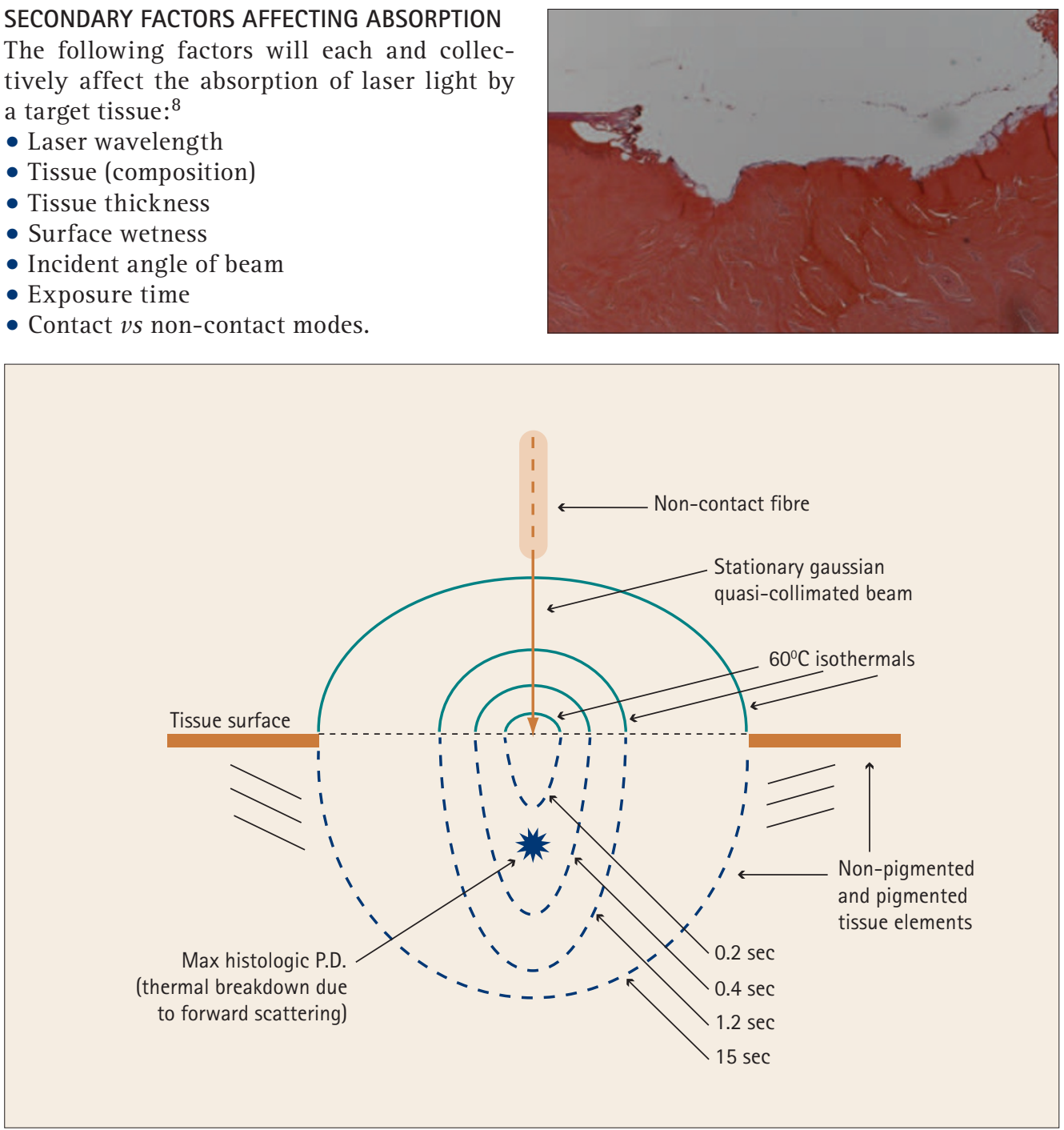

Laser wavelength and tissue composition

Tissue elements that absorb laser light energy are termed chromophores. Oral tissue can be considered as composed of one or more chromophores - haemoglobin, melanin and allied pigmented proteins, (carbonated) hydroxyapatite, and water. Relative to the spectrum of laser wavelengths currently in use in clinical dentistry, the absorption coefficients of these chromophores are shown in Figure 3.

In using the minimum amount of incident energy to effect a desired tissue change, it can be summarised that, with regard to current use of lasers in clinical practice, any tissue that is predominately pigmented will absorb shorter, ie visible and near infra-red, laser wavelengths, whereas non-pigmented tissue will absorb longer wavelengths. In addition, absorption peaks of water and (carbonated) hydroxyapatite, coincident with Er:YAG, Er:YSGG and $\mathrm{CO}_{2}$ wavelengths, would support the potentially advantageous use of these lasers in hard tissue management. However, the prime interaction based on absorption peaks is often compromised by other factors, as discussed below.
Tissue thickness and depth of penetration

The existence of water as a constituent of all living tissue will influence the penetration of longer wavelength laser light, whilst non-pigmented surface components will prove transmissive to shorter wavelengths, leading to potentially deep penetration. In this way, whereas $\mathrm{CO}_{2}$ wavelength might penetrate oral epithelium to a depth of 0.1-0.2 mm, $\mathrm{Nd}$ : YAG and diode wavelengths can result in an equivalent-power penetration of 4-6 $\mathrm{mm} .^{9}$

\section{Incident angle of beam and surface wetting}

The control of laser-tissue interaction is maximised if the incident beam is perpendicular to the tissue surface. As the incident angle reduces towards the refractive angle of the tissue surface, so the potential for true light reflection becomes more apparent, with an associated reduction in tissue change. ${ }^{10}$ Surface wetness is less of a problem for shorter wavelength use.

\section{Emission mode and exposure time}

As discussed earlier, the emission mode will affect the potential for any peak energy values; equally the thermal relaxation benefits, both inherent with low duty cycle
Fig. 9 Diode laser and oral epithelium. Due to deeper penetration and conductive heat effects, the zone of ablation is more rounded in outline

Fig. 10 Diode laser cutting and soft tissue schematic 
Fig. 11 Theoretical zone of tissue change associated with hard dental tissue exposure to laser light
Fig. 12 Class $V$ cavity preparation carried out using an Er:YAG laser
Fig. 13 Schematic progressive micro-explosion ablation of dental hard tissue with mid-infrared (Er: YAG, Er,Cr:YSGG) laser wavelengths

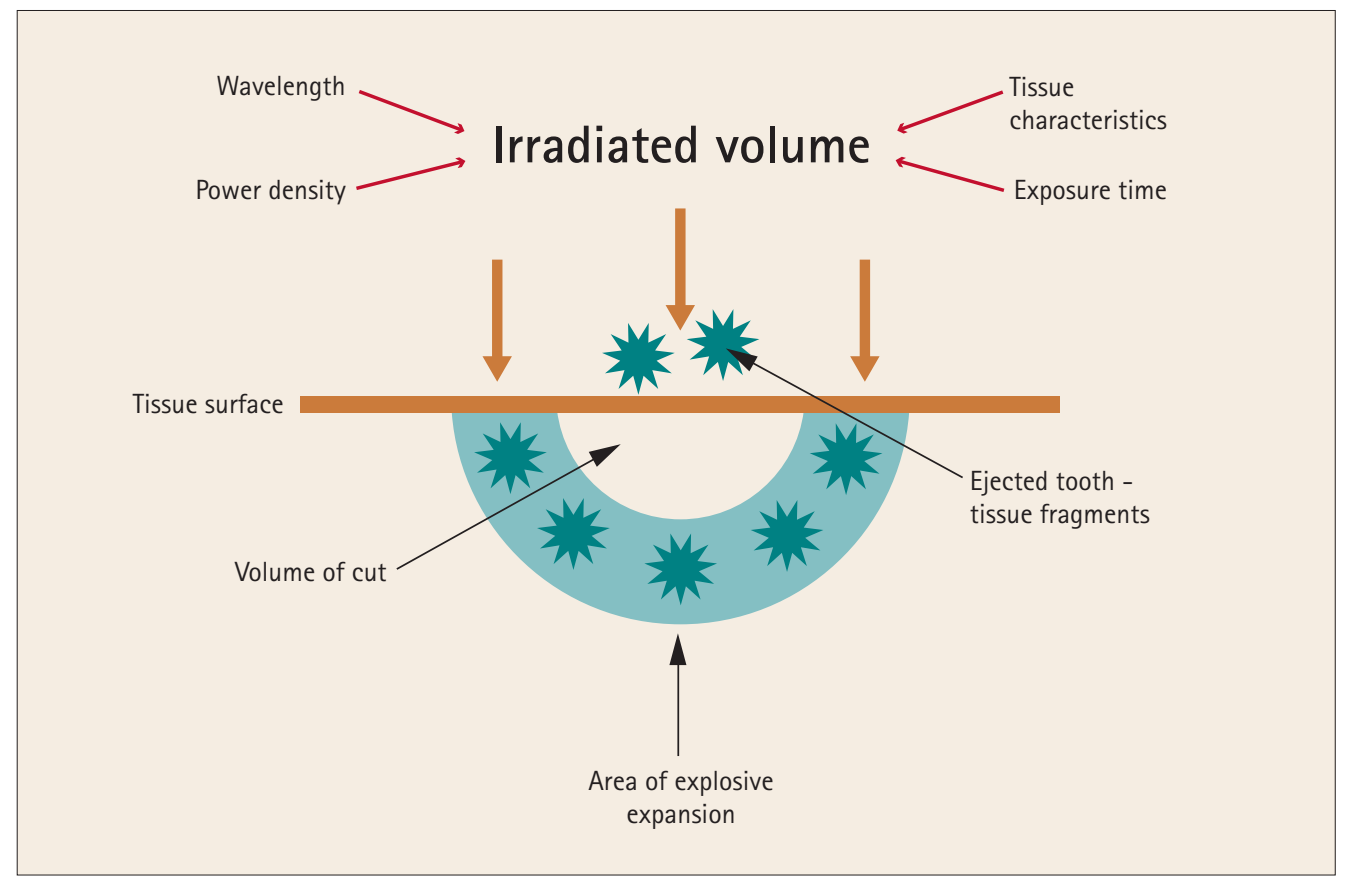

emissions and applied through power-off intervals, will enhance therapeutic tissue management.

\section{Contact vs non-contact modes}

Laser light will undergo some divergence on exit from a quartz fibre delivery system and most non-fibre systems (hollow waveguide

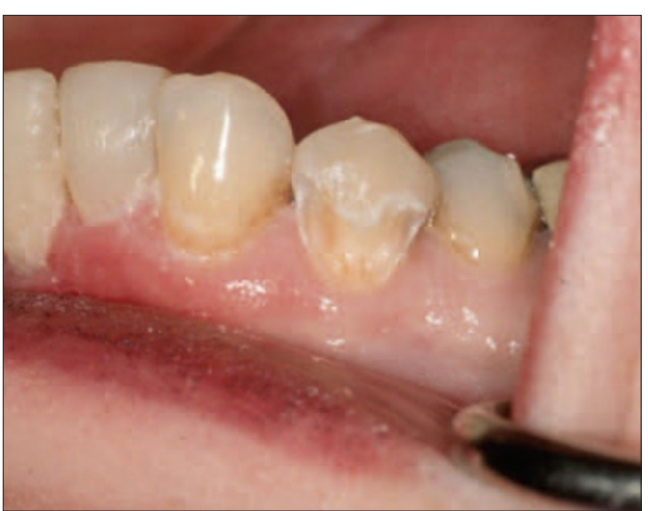

and articulated arm) use a focusing lens. Consequently, the 'spot size' of the beam, relative to the target tissue, will determine the concentration of laser energy - fluence and power density - being delivered over an area. ${ }^{11}$ The spot size will change with distance for any delivery system - it will increase with distance for a fibre-optic delivered beam and change relative to the focal length of the lens in those delivery systems where a focusing hand-piece is used (Fig. 4).

It follows, therefore, that during any lasertissue interaction the concentration of energy being delivered to a target site can be modified and controlled by moving the hand-piece back and forth. In this way, thermal changes can be effectively controlled.

\section{LASER LIGHT AND SOFT TISSUE}

Figures 5 and 6 depict a schematic and clinical example of an ideal surgical laser interaction with soft tissue. Assuming a correct

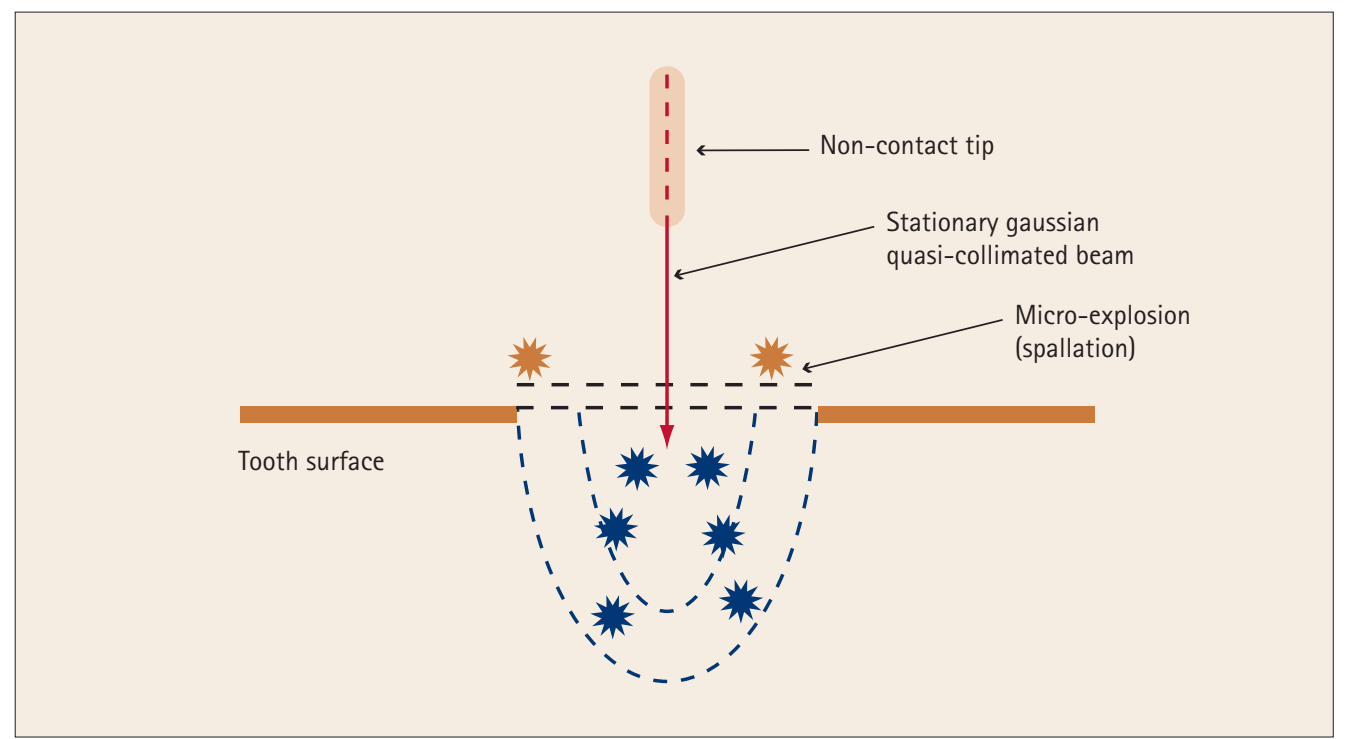


incident wavelength, using correct delivery parameters, a central zone of tissue ablation is surrounded by an area of irreversible protein denaturation (coagulation, eschar). Surrounding this, along a thermal gradient, a reversible, reactionary zone of oedema will develop. The depth and extent of this tissue change will differ with laser wavelength, being more superficial in nature with longer wavelengths, with less oedema, and deeper with greater oedema with shorter wavelengths.

\section{Soft tissue cutting dynamics and laser} wavelength

A distinct difference can be observed between short and long laser wavelengths, in their interaction with soft tissue. Longer wavelengths, being maximally absorbed by water-based chromophores, exhibit a sharp surface-configured interaction, with little sub-surface disruption ${ }^{12}$ (Figs 7 and 8).

Shorter wavelengths give rise to a greater zone of deeper disruption, accentuated through conductive heat transfer (Figs 9 and 10).

Generally, with laser use on soft tissue, there is minimal or no bleeding. This is due to a combination of small vessels being sealed through tissue protein denaturation and stimulation of Factor VII production in clotting. The incision line will at best equal the beam diameter, and the production of a surface coagulum obviates need for sutures. Healing will always be by secondary intention and little or no scar formation is seen to occur. Compared to scalpel incisions, the healing time is delayed, although, due to the coagulum layer, there is little potential for bacterial contamination of the wound. ${ }^{13}$

\section{LASER USE AND HARD TISSUE}

Figures 11 and 12 illustrate the theoretical and clinical effects of long wavelength laser light on hard dental tissue. Potentially, unlike laser wavelengths and soft tissue chromophores, there are three wavelengths that will interact with dental hard tissue. The predominant two are Er:YAG $(2,940 \mathrm{~nm})$ and Er,Cr:YSGG $(2,780 \mathrm{~nm}),{ }^{14}$ together with $\mathrm{CO}_{2}$ $(10,600 \mathrm{~nm})$. These wavelengths have an affinity for (carbonated) hydroxyapatite and water chromophores. However, although the water content of enamel and dentine is very low (3-5\% in enamel and 13-15\% in dentine), it is the configuration of the emission modes in commercial dental lasers that defines the underlying nature of tissue ablation. The commonly-employed wavelength of $\mathrm{CO}_{2}$ lasers in dentistry $(10,600 \mathrm{~nm})$ has a high absorption in water, but a relatively low absorbance in hydroxyapatite when compared to the 9,600 $\mathrm{nm}$ wavelength found in laboratory $\mathrm{CO}_{2}$ lasers. In addition, the $10,600 \mathrm{~nm} \mathrm{CO}$ laser emits in continuous and gated-continuous wave modes, which not only renders the

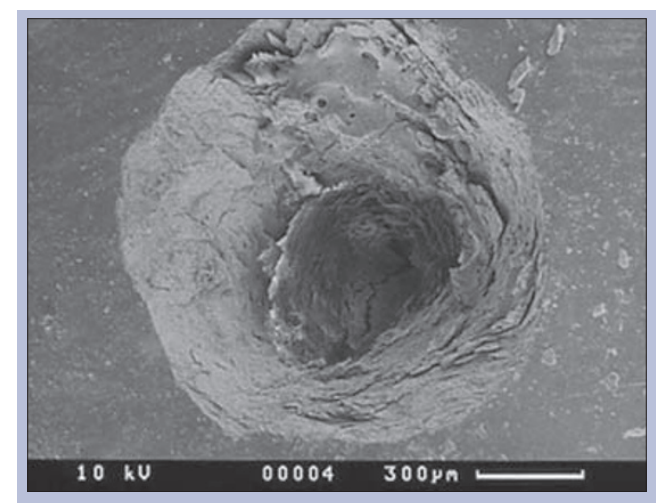

Fig. 14 Scanning electron micrographs showing the effects of Er: YAG laser light on enamel. Note the fragmentation of tissue edges and lack of conductive thermal effects
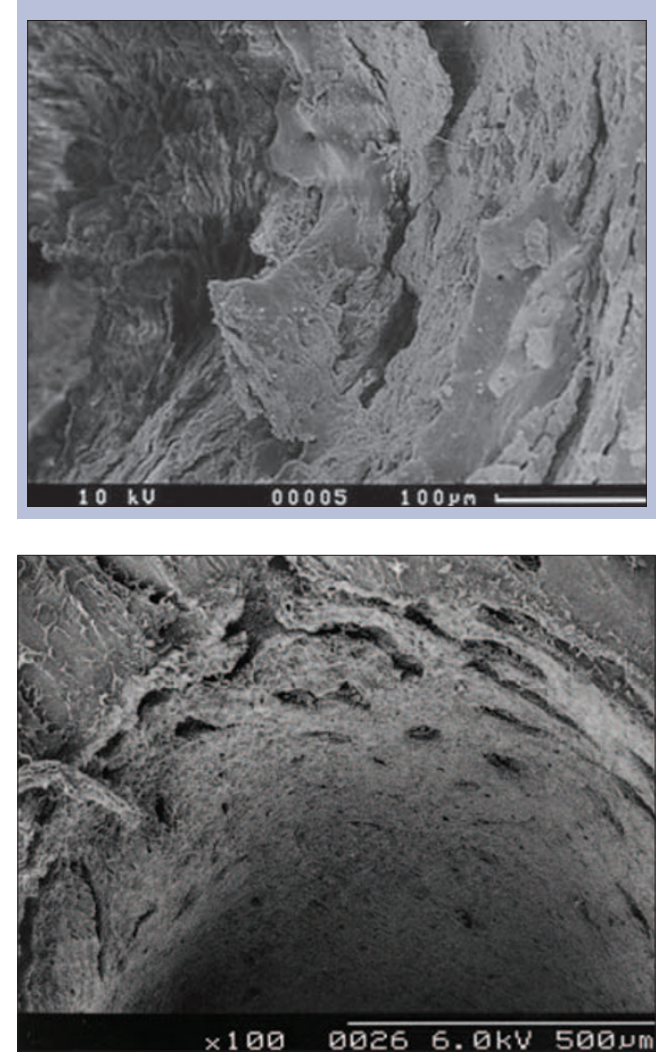

Fig. 15 Scanning electron micrograph showing the cutting effect of Er:YAG laser light on bone average power output low, but also significantly reduces the thermal relaxation potential. This can have disastrous effects with dental hard tissues. ${ }^{15}$

Equally, the use of shorter wavelengths, eg Nd:YAG (1,064 nm), which have no appreciable absorption in dental hard tissue, can lead to thermal cracking and amorphous change in the hydroxyapatite crystal structure. In addition, there is a potential for high intra-pulpal temperature rise, due to transmission of this laser energy through enamel and dentine. ${ }^{16}$

\section{Hard tissue cutting dynamics and laser} wavelength

Both erbium laser wavelengths have freerunning pulsed emission modes, which give rise to high peak power levels ( $>1,000$ Watts). Such power levels result in an instantaneous, explosive vaporisation of the water content of enamel and dentine, which leads to dissociation of the tissue and ejection of micro-fragments (Figs 13 and 14). In addition, both lasers 
Fig. 16 Pre-operative combined crown lengthening, fixed and removable prosthetics case
Fig. 17 Use of $\mathrm{CO}_{2}$ laser to remove excess gingival tissue and re-contour soft tissue profile
Fig. 18 Healing soft tissue at two weeks
Fig. 19 Completed treatment at six weeks
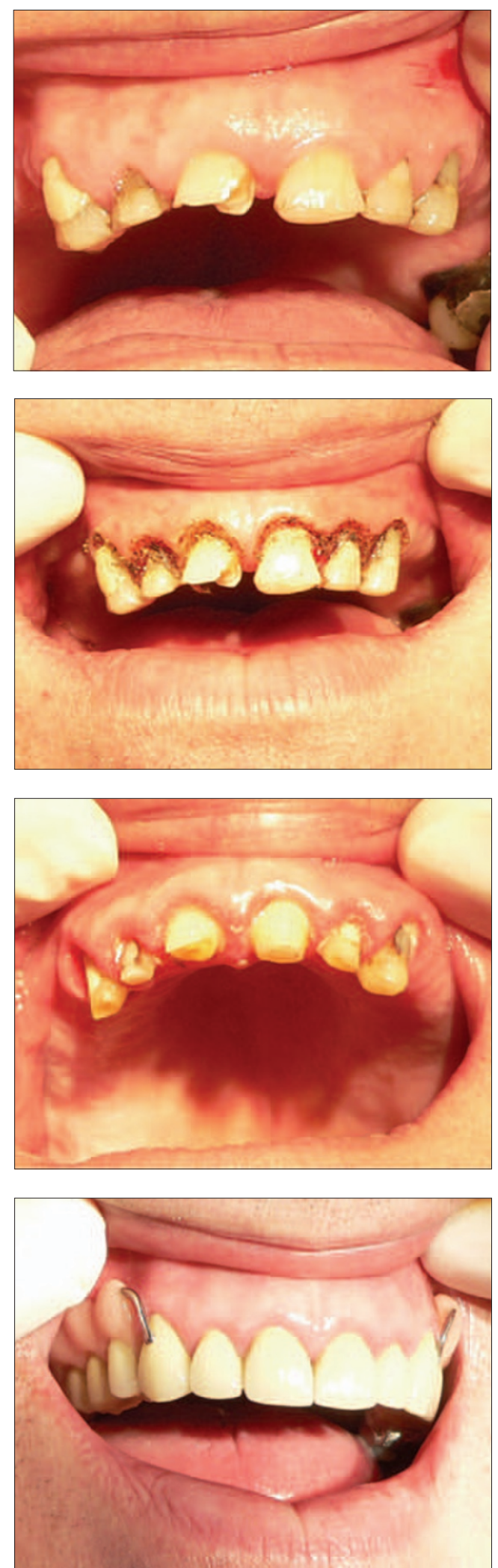

use co-axial water spray to aid dispersal of ablated tissue and to cool the target. ${ }^{17}$ In comparison with rotary instrumentation, pulpal temperature rise is minimal when erbium laser wavelengths are employed. ${ }^{18}$ As such, cavity preparation proceeds without surface cracking.

It has been shown that the crater depth and ablation volume during enamel and dentine ablation proceed in a linear relationship with time. However, if the auxiliary water spray is prevented from reaching the cavity, the build-up of ablation debris prevents further cutting and there is consequent heat production.

Laser ablation of bone with erbium laser wavelengths proceeds in a similar fashion. The higher water content and lower density of bone compared to enamel allows faster cutting, through dislocation of hydroxyapatite and cleavage of the collagen matrix (Fig. 15).

This ease of cutting places the use of Er: YAG and Er,Cr:YSGG laser wavelengths as the preferred choice for laser bone ablation when compared to other wavelengths, although there may be slightly higher heating effects with Er:YSGG. ${ }^{19}$

The use of erbium YAG and YSGG laser wavelengths in the ablation and management of root dentine and cementum results in efficient and clean removal of tissue, due to the relatively high water content. The correct use of laser power parameters, together with adequate water spray, prevents direct thermal damage to the tissue structure, witnessed by the absence of melting or cracking. ${ }^{20}$ As with other dental hard tissue, the use of $\mathrm{CO}_{2}$ laser, in its dentally configured form, should be avoided. ${ }^{21}$

\section{BENEFITS OF LASER-TISSUE INTERACTION}

From the above, a number of benefits of laser use in the treatment of soft and hard tissue can be listed as follows:

Soft tissue:

- Ability to cut, coagulate, ablate or vaporise target tissue elements

- Sealing of small blood vessels (dry field of surgery)

- Sealing of small lymphatic vessels (reduced post-operative oedema)

- Sterilising of tissue (due to heat buildup and production of eschar layer and destruction of bacterial forms)

- Decreased post-operative tissue shrinkage (decreased amount of scarring).

Hard tissue:

- Ability to selectively ablate carious dental tissue (faster ablation due to higher water content)

- Reduced peri-operative cracking compared to rotary instrumentation

- Scope for minimally-invasive restorative treatment of early caries

- Reduced pulpal temperature rise

- Cavity sterilisation.

Examples of the advantages of laser-tissue interaction in delivering general dental treatment are given in Figures 16-23. The ability to ablate diseased or excess tissue elements whilst minimising unwanted extraneous effects, and to combine otherwise-staged treatment, defines real benefit to both the clinician and the patient. 

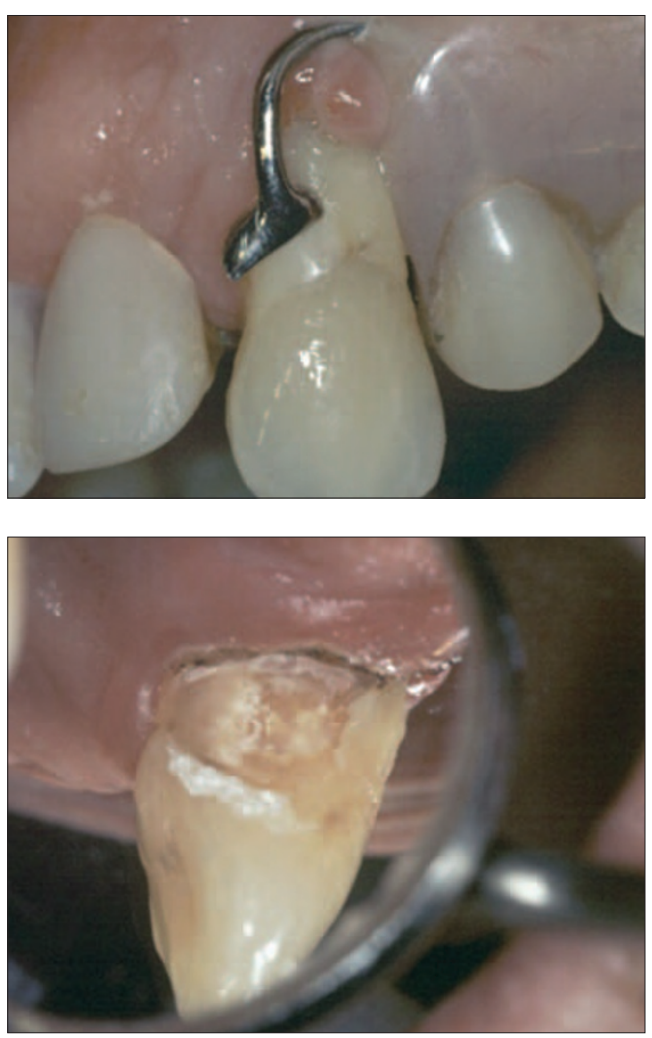

1. Knappe V, Frank F, Rohde E. Principles of lasers and biophotonic effects. Photomed Laser Surg 2004; 22: 411-417.

2. Ball K A. Lasers: the perioperative challenge. 2nd ed. pp 14-17. St Louis: Mosby-Year Book, 1995.

3. Moshonov J, Stabholz A, Leopold Y, Rosenberg I, Stabholz A. Lasers in dentistry. Part B - interaction with biological tissues and the effect on the soft tissues of the oral cavity, the hard tissues of the tooth and the dental pulp. Refuat Hapeh Vehashinayim 2001; 18: 21-28, 107-108.

4. Hillenkamp F. Laser radiation tissue interaction. Health Phys 1989; 56: 613-616.

5. van Gemert M J, Lucassen G W, Welch A J. Time constants in thermal laser medicine: II. Distributions of time constants and thermal relaxation of tissue. Phys Med Biol 1996; 41: 1381-1399.

6. Anvari B, Motamedi M, Torres J H, Rastegar S, Orihuela E. Effects of surface irrigation on the thermal response of tissue during laser irradiation. Lasers Surg Med 1994; 14: 386-395.

7. Pinheiro A L, Browne R M, Frame J W, Matthews J B. Mast cells in laser and surgical wounds. Braz Dent J 1995; 6: 11-15.

8. Dederich D N. Laser/tissue interaction: what happens to laser light when it strikes tissue? J Am Dent Assoc 1993; 124: 57-61.

9. Ball K A. Lasers: the perioperative challenge. 2nd ed. pp 19. St Louis: Mosby-Year Book, 1995.

10. Gaspar L, Kasler M, Orosz M. Effect of $\mathrm{CO}_{2}$ laser beam angle of incidence in the oral cavity. J Clin Laser Med Surg 1991: 9: 209-213.

11. Myers T D, Murphy D G, White J M, Gold SI. Conservative soft tissue management with the low-powered pulsed

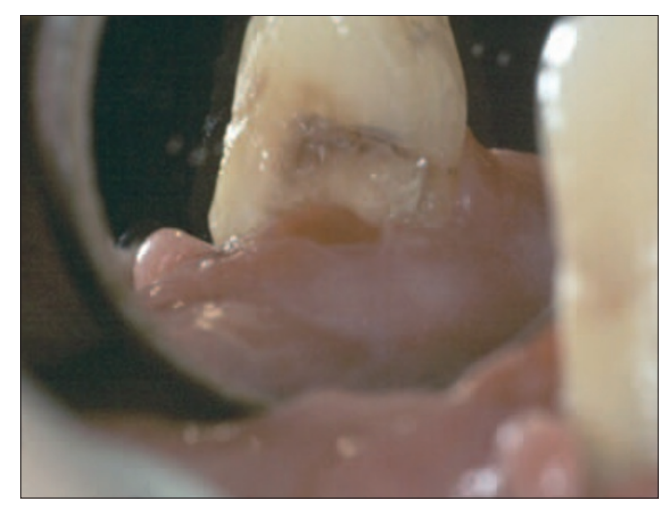

Fig. 20 (left) Denture-induced epulis and class V cavity at UL canine

Fig. 21 (right) Partial denture removed to show hard and soft tissue lesions

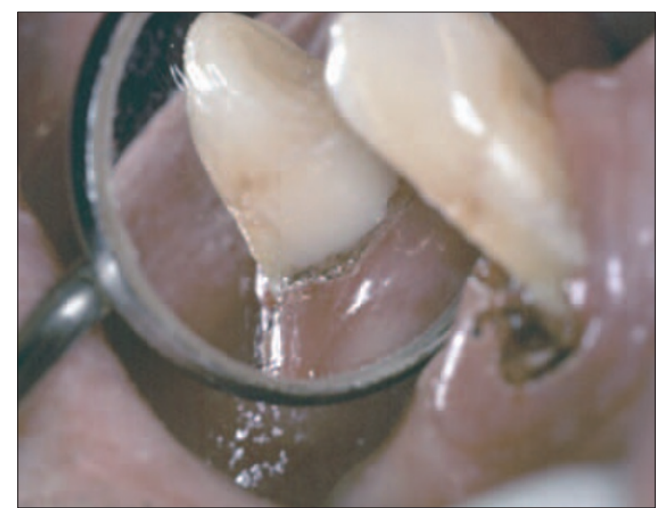

Fig. 22 (left) Hyperaemic epulis removed using diode laser to induce haemostasis, cervical margin of cavity exposed using $\mathrm{CO}_{2}$ laser and cavity preparation completed using Er:YAG laser

Fig. 23 (right) Completed singlevisit treatment
Nd:YAG dental laser. Pract Periodont Aesthet Dent 1992; 4:6-12.

12. Fisher J C. Photons, physiatrics, and physicians: a practical guide to understanding laser light interaction with living tissue, part I. J Clin Laser Med Surg 1992; 10: 419-426.

13. Fisher S E, Frame J W, Browne R M, Tranter R M. A comparative histological study of wound healing following $\mathrm{CO}_{2}$ laser and conventional surgical excision of canine buccal mucosa. Arch Oral Biol 1983; 28: 287-291.

14. Wigdor H, Abt E, Ashrafi S, Walsh JT Jr. The effect of lasers on dental hard tissues. J Am Dent Assoc 1993; 124: 65-70.

15. Launay Y, Mordon S, Cornil A, Brunetaud J M, Moschetto Y. Thermal effects of lasers on dental tissues. Lasers Surg Med 1987; 7: 473-477.

16. Allen D J. Thermal effects associated with the Nd/YAG dental laser. Angle Orthod 1993; 63: 299-303.

17. Hoke J A, Burkes E J Jr, Gomes E D, Wolbarsht M L. Erbium: YAG (2.94 mum) laser effects on dental tissues. J Laser App/ 1990: 2: 61-65.

18. Rizoiu I, Kohanghadosh F, Kimmel A I, Eversole L R. Pulpal thermal responses to an erbium, chromium:YSGG pulsed laser hydrokinetic system. Oral Surg Oral Med Oral Pathol Oral Radiol Endod 1998; 86: 220-223.

19. Jahn R, Bleckmann A, Duczynski E et al. Thermal side effects after use of the pulsed IR laser on meniscus and bone tissue. Unfallchirurgie 1994; 20: 1-10.

20. Sasaki K M, Aoki A, Ichinose S, Ishikawa I. Morphological analysis of cementum and root dentin after Er:YAG laser irradiation. Lasers Surg Med 2002; 31: 79-85.

21. Anic I, Dzubur A, Vidovic D, Tudja M. Temperature and surface changes of dentine and cementum induced by $\mathrm{CO}_{2}$ laser exposure. Int Endod J 1993; 26: 284-293. 